\title{
Incorporation de tourteau de colza obtenu par pression dans une ration d'engraissement chez le taurillon. I. Ingestion, digestibilité et fermentation dans le rumen
}

\author{
AP Mayombo ${ }^{1 *}$, P Baldwin 1, JP Wathelet ${ }^{2}$, \\ M Marlier ${ }^{2}$, L Istasse 1 \\ ' Nutrition animale, faculté de médecine vétérinaire, université de Liège, \\ B 43, Sart-Tilman, 4000 Liège ; \\ 2 UER chimie générale et organique, faculté des sciences agronomiques, \\ 5030 Gembloux, Belgique
}

(Reçu le 27 octobre 1995 ; accepté le 12 juin 1996)

\begin{abstract}
Summary - Incorporation of rapeseed meal extracted by pressure in a diet for growing fattening bulls. I. Intake, digestibility and fermentation in the rumen. Intake, digestibility, degradation kinetic and fermentation were studied with bulls offered fattening diets with four different incorporation rates of rapeseed meal obtained by pressure; the ether extract content was $8.6 \%$ and the glucosinolate content $17,6 \mu \mathrm{molg}$. The control diet was made of sugar beet pulp, cereals, soya bean meal and linseed meal. In the three other diets, nitrogen from rapeseed meal provided 33, 66 or $100 \%$ of nitrogen from soya bean meal or linseed meal. The intakes of the control diet were $94.3 \pm 7.3 \mathrm{~g} / \mathrm{kg}$ metabolic body weight. Intakes were maintained high in the diet with 33,66 or $100 \%$ of protein from rapeseed meal at $93.5 \pm 7.7 ; 93.0 \pm 5.0$ and $93.5 \pm 7.7 \mathrm{~g} / \mathrm{kg}$, respectively. The apparent digestibility of rapeseed meal in the ration containing only rapeseed meal was high at $74.9 \pm 1.9 \%$ for dry matter, $76.5 \pm 2.1 \%$ for organic matter, $69.9 \pm 3.9 \%$ for nitrogen, $59.1 \pm 4.8 \%$ for $\mathrm{ADF}$ and $74.6 \pm 6.9 \%$ for ether extract. Dry matter of rapeseed meal was less degradable $(57.8$ $\pm 5.0 \%)$ than that of soya bean meal $(65.5 \pm 2.6 \%)$ or of linseed meal $(61.6 \pm 4.2 \%)$ but was not as well protected than that of protected soya bean meal $(43.6 \pm 2.6 \%)(P<0.001)$. Similar trends were observed for the degradability of nitrogen $(P<0.001)$. Ether extract of rapeseed meal was more degradable than that of linseed meal $(P<0.001)$. There were no significant effects of the incorporation rate of rapeseed meal on the $\mathrm{pH}$ in the rumen. The fermentations were mainly of the acetate
\end{abstract}

\footnotetext{
* Correspondance et tirés à part

Fax : (32) 43664122 ; courriel : Mayombo@state.fmv.ulg.ac.be
} 
type with usual concentrations of propionate, butyrate, total volatile fatty acids, glucose or alpha amino nitrogen. Ammonia concentration was higher with the control diet and lower with the diet with $100 \%$ of protein from rapeseed meal. Fatty acids of rapeseed meal were more protected against saturation by the rumen microorganisms than in linseed meal.

\section{rapeseed meal / bull / intake / digestibility / fermentation}

Résumé — L'ingestion, la digestion, la cinétique de dégradation ainsi que les fermentations dans le rumen ont été étudiées chez les taurillons recevant des rations d'engraissement contenant différents taux d'incorporation d'un tourteau de colza à $8,6 \%$ d'extrait éthéré obtenu par pression et contenant une faible quantité de glucosinolates $(17,6 \mu \mathrm{mol} / \mathrm{g})$. Quatre rations ont été utilisées. La ration témoin était composée de pulpes séchées, céréales, tourteau de soja et de lin. Dans les trois autres rations, les matières azotées du tourteau de colza ont remplacé à raison de 33,66 et $100 \%$ celles des tourteaux de soja et de lin. La consommation de la ration témoin a été de $94,3 \pm 7,3 \mathrm{~g} / \mathrm{kg}$ de poids métabolique. L'incorporation du tourteau de colza a permis le maintien d'ingestions élevées puisque les consommations avec les rations, dont 33,66 et $100 \%$ des matières azotées provenant du tourteau de colza, ont été respectivement de $93,5 \pm 7,7 ; 93,0 \pm 5,0$ et $93,5 \pm 7,7 \mathrm{~g} / \mathrm{kg}$ de poids métabolique. La digestibilité apparente du tourteau de colza dans la ration qui contenait uniquement le tourteau de colza a été particulièrement élevée : $74,9 \pm 1,9 \%$ pour la matière sèche ; $76,5 \pm 2,1 \%$ pour la matière organique ; $69,9 \pm 3,9 \%$ pour les matières azotées ; 59,1 $\pm 4,8 \%$ pour l'acid detergent fiber (ADF) et $74,6 \pm 6,9 \%$ pour l'extrait éthéré. La matière sèche du tourteau de colza a été moins dégradable $(57,8 \pm 5,0 \%)$ que celle des tourteaux de soja $(65,4 \pm 2,6 \%)$ et de lin $(61,6 \pm 4,2 \%)$, mais n'a pas été aussi fortement protégée que celle du tourteau de soja protégé $(43,6 \pm 2,6 \%)(p<0,001)$. Des tendances similaires ont été observées avec la dégradabilité des matières azotées du tourteau de colza et les différences ont été significatives $(p<0,001)$. L'extrait éthéré du tourteau de colza a été plus dégradable que celui du tourteau de lin $(p<0,001)$. Il n'y a pas eu d'effets significatifs de l'incorporation de tourteau de colza sur le $\mathrm{pH}$ dans le rumen. Les fermentations ont été de type acétique ; les proportions d'acides propionique et butyrique ont été classiques. Il en va de même pour les concentrations en acides gras volatils totaux, glucose, et azote alpha aminé. La concentration en ammoniaque a été plus élevée avec la ration témoin et plus faible avec la ration contenant $100 \%$ des matières azotées provenant du tourteau de colza. Les acides gras du tourteau de colza ont été plus protégés contre les saturations par les microorganismes du rumen que ceux du tourteau de lin.

\section{tourteau de colza / taurillon / ingestion / digestibilité / fermentation}

\section{INTRODUCTION}

La conjoncture économique actuelle et la réforme de la politique agricole commune (PAC) conduisent les agriculteurs vers la diversification des cultures. Parmi celles-ci, il faut citer la culture de colza en vue de son utilisation industrielle pour la production de biocarburants. Des usines destinées à la trituration des oléagineux de taille généralement moyenne ou petite de type coopérative, se développent dans les régions de production des oléagineux. Elles sont équipées de systèmes d'extraction mécanique avec un rendement d'extraction moyen et, par conséquent, une teneur très élevée en matières grasses dans le tourteau ; cette dernière est comprise entre 12 et $15 \%$. Lorsqu'un prétraitement à chaud est ajouté au système, le rendement est amélioré (teneur proche de $8 \%$ en matières grasses).

Une particularité du tourteau de colza est le peu d'intérêt que lui portent les fabricants d'aliments concentrés en raison de l'existence de 
principes antinutritionnels (Bell, 1984) en quantité très variable et fonction du pays de production des graines. En Europe occidentale et en Amérique du Nord, les variétés retenues sont celles qui ont été sélectionnées pour leur faible teneur en glucosinolates soit des teneurs comprises entre 20 et $35 \mu \mathrm{mol} / \mathrm{g}$ de matière sèche (MS) (variété 00 ) ; le rendement à l'hectare est moyennement élevé soit environ 3 tonnes. À l'opposé, en Asie, ce sont les variétés les plus productives qui sont utilisées. Elles contiennent des quantités importantes de principes antinutritionnels.

Il existe donc dans nos régions du tourteau de colza à fortes teneurs en matières grasses provenant de variété à faibles teneurs en glucosinolates. Il était donc utile de procéder à la caractérisation de la valeur alimentaire et au suivi du devenir de différents principes antinutritionnels contenus dans ce type de tourteau. Dans une revue récente consacrée à l'utilisation de matières grasses dans les rations d'engraissement de

Tableau I. Composition chimique et valeur nutritionnelle du tourteau de colza rapportées à la matière sèche.

$\begin{array}{lc}\text { Composition chimique } & \\ \text { Matière sèche }(\%) & 93,4 \\ \text { Matière organique }(\%) & 93,3 \\ \text { Matière azotée }(\%) & 37,8 \\ \text { Extrait éthéré }(\%) & 8,6 \\ \text { ADF }(\%) & 27,1 \\ \text { Glucosinolates totaux ( } \% \text { mole/g) } & 17,6 \\ \text { Ca }(\mathrm{g} / \mathrm{kg}) & 9,6 \\ \mathrm{P}(\mathrm{g} / \mathrm{kg}) & 12,6 \\ \mathrm{Na}(\mathrm{g} / \mathrm{kg}) & 0,3 \\ \mathrm{Mg}(\mathrm{g} / \mathrm{kg}) & 4,6 \\ \mathrm{~K}(\mathrm{~g} / \mathrm{kg}) & 13,7 \\ \mathrm{Cu}(\mathrm{mg} / \mathrm{kg}) & 4,2 \\ \mathrm{Zn}(\mathrm{mg} / \mathrm{kg}) & 65,1 \\ \mathrm{Mn}(\mathrm{mg} / \mathrm{kg}) & 80,8 \\ & \\ \text { Valeur nutritionnelle } & \\ \text { UFL } & 1,11 \\ \text { UFV } & 1,07 \\ \text { PDIE }(\mathrm{g}) & 152 \\ \text { PDIN }(\mathrm{g}) & 259 \\ & \end{array}$

bovin, Clinquart et al (1995) ont décrit les effets d'une teneur élevée en matières grasses sur les ingestions, la digestibilité, les performances et la qualité de la carcasse et de la viande. D'autre part, Subuh et al (1994) rapportent que la dégradabilité dans le rumen serait moindre pour les variétés de colza à faible teneur en glucosinolates. L'approche expérimentale de caractérisation d'un tourteau de colza produit par pression a donc consisté à incorporer des quantités croissantes de ce tourteau dans une ration d'engraissement de taurillons. Les données obtenues concernent l'ingestion, la digestibilité, les paramètres de fermentation dans le rumen et le devenir des principes antinutritionnels. Elles font l'objet d'une série de 2 articles, le premier traite l'aspect zootechnique et le second se rapporte aux principes antinutritionnels.

\section{MATÉRIEL ET MÉTHODES}

\section{Production du tourteau}

Des graines de colza de la variété Samourai ont été utilisées. Il s'agit d'une variété à faible teneur en glucosinolates $(17,6 \mu \mathrm{mol} / \mathrm{g}$ MS, variété 00$)$. Les graines ont été traitées dans une installation de taille moyenne d'une coopérative disposant d'une presse couplée à une unité de prétraitement à chaud. Les graines ont d'abord été broyées, à température ambiante, entre deux rouleaux lisses. Le produit a ensuite été acheminé dans un cuiseur où la cuisson à $80^{\circ} \mathrm{C}$ a duré 25 minutes ; la teneur en eau est passée de 9 à $15 \%$. Ensuite, on a procédé à une phase de séchage à $110^{\circ} \mathrm{C}$ pendant 10 minutes ; l'humidité est redescendue à $4 \%$. Cette farine est passée alors dans la presse pendant moins d'une minute ; la température s'élevant à $150^{\circ} \mathrm{C}$. La température du tourteau est ensuite diminuée par passage dans un refroidisseur à eau, en vue de l'amener à température ambiante et à une teneur en humidité d'environ $8 \%$. La composition chimique du tourteau de colza est reprise dans le tableau I. Les principales caractéristiques sont des teneurs élevées en matières azotées $(37,8 \%)$, extrait éthéré $(8,6 \%)$ et acid detergent fiber-ADF $(27,1 \%)$. 
Il est intéressant de noter également des teneurs importantes en $\mathrm{Ca}, \mathrm{P}, \mathrm{Mg}, \mathrm{Zn}$ et $\mathrm{Mn}$.

\section{Formulation des mélanges}

L'étude du tourteau de colza a été réalisée à partir de son incorporation dans une ration d'engraissement pour taurillons à base de pulpes séchées. Ce choix se justifie par le fait que le mélange d'engraissement à base de pulpes séchées constitue $90 \%$ des apports en MS des taurillons, les $10 \%$ restant étant constitués par la paille. Comme l'installation ne disposait pas de râtelier, la paille était incorporée au mélange grâce à une mélangeuse distributrice. Le mélange de réference était composé de pulpes séchées (42\%), de céréales et issues de meunerie ( $36 \%$ ), de tourteaux de soja et de lin ( $17 \%)$, de mélasse $(4 \%)$ et d'un mélange minéral vitaminé $(1 \%)$. Il s'agit d'un mélange fréquemment utilisé pour l'engraissement (Clinquart et al, 1991) et dont la composition chimique se caractérise par une faible teneur en matières grasses $(3,2 \%)$, une teneur en matières azotées totales de $16 \%$, une teneur en ADF de $11 \%$ et des teneurs en Ca et $P$ respectivement de 8,4 et $4,3 \mathrm{~g} / \mathrm{kg}$ (tableau II). Trois autres mélanges ont été formulés en vue de remplacer les apports en matières azotées des tourteaux de soja et de lin par les matières azotées du tourteau de colza. Quatre niveaux de tourteau de colza ont donc été étudiés correspondant à $0,33,66$ et $100 \%$ de matières azotées des tourteaux provenant du tourteau de colza. Les compositions centésimales et chimiques des mélanges sont données dans le tableau II. Il faut

Tableau II. Composition centésimale et chimique des mélanges distribués.

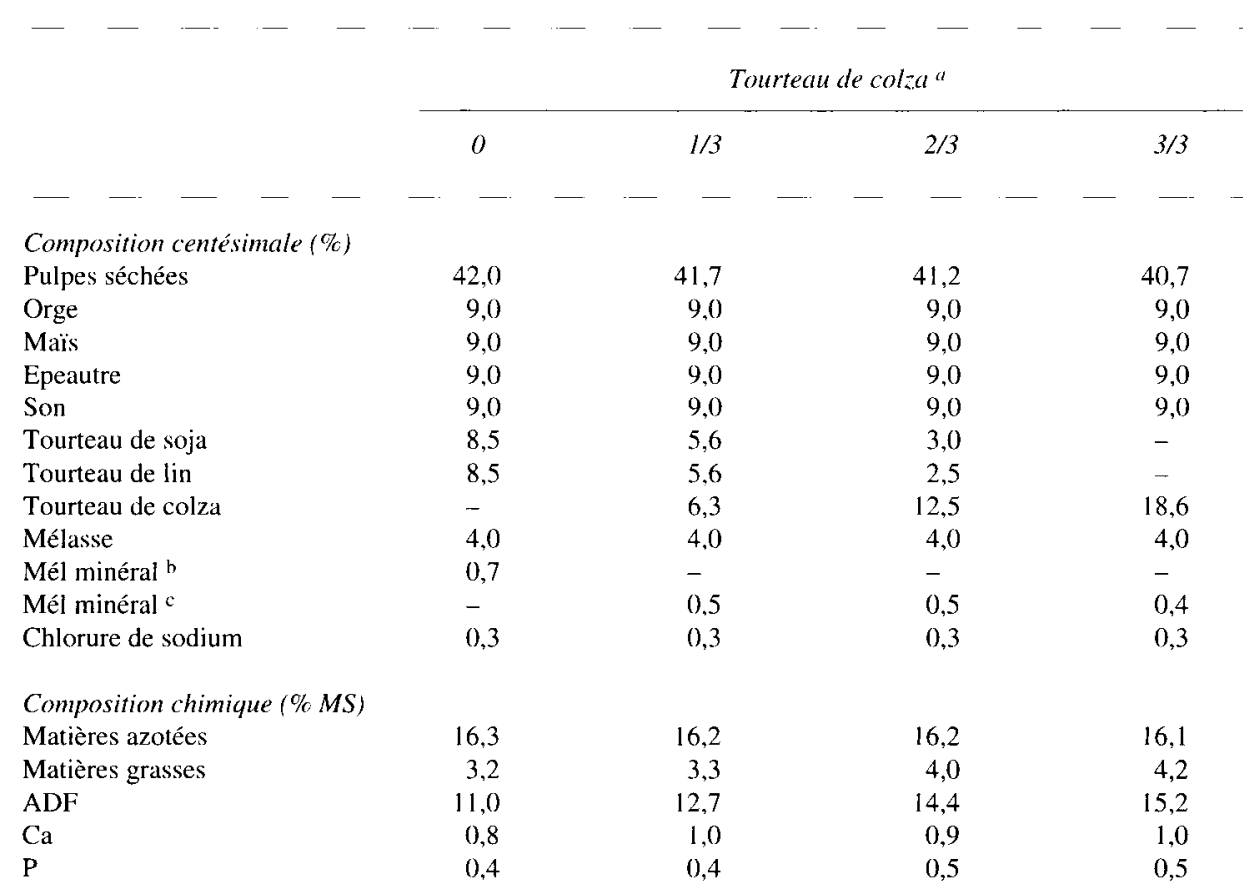

"Les chiffres $0,1 / 3,2 / 3$, et $3 / 3$ se référent aux proportions de proteines apportées par le tourteau de colza dans l'ensemble des proteines apportées par les tourteaux ; ${ }^{\mathrm{h}} \mathrm{Ca}: 8 \%$ et $\mathrm{P}: 16 \% ; \mathrm{Ca}: 16 \%$ et $\mathrm{P}: 3 \%$. 
noter que pour maintenir les teneurs en $\mathrm{P}$ inférieures à $5 \mathrm{~g} / \mathrm{kg} \mathrm{MS}$, il a fallu utiliser un mélange minéral très pauvre en $\mathrm{P}$ lors de l'incorporation du tourteau de colza en grande quantité.

\section{Animaux et mesures}

Un total de 8 taurillons de race Blanc Bleu de conformation mixte ont été utilisés dans un modèle de 2 carrés latins $4 \times 4$. Les animaux pesaient à mi-expérience en moyenne $530 \mathrm{~kg}$. Ils étaient porteurs d'une canule du rumen. Ils ont séjourné sur des stalles à métabolisme non équipées de ratelier. Chaque période du carré latin avait une durée de $\mathbf{4 2}$ jours avec une période de transition de 7 jours.

Les ingestions ont été proches de l'ad libitum par adaptation des quantités d'aliments distribuées en fonction de l'apparition des refus. Les quantités ingérées ont été enregistrées quotidiennement. La digestibilité apparente des rations a été mesurée par collecte totale des féces pendant une période de 7 jours à la fin de chaque période du carré latin. La digestibilité apparente du tourteau de colza a été calculée par différence (Schneider et Flatt, 1975) en se basant sur les coefficients de digestibilité proposés par Inra (1988) pour les autres composants de la ration.

Afin de déterminer l'influence de quantités croissantes de matières azotées de tourteau de colza sur l'activité microbienne dans le rumen, la dégradabilité de la MS de 8 aliments a été déterminée par la technique des sachets de nylon (Mehrez et Ørskov, 1977). Il s'agissait dans un premier groupe, de tourteau de colza, de tourteau de lin et de tourteaux de soja protégé au formaldéhyde ou non, soit 4 aliments riches en matières azotées. L'autre groupe, composé d'aliments moins riches en matières azotées comprenait 2 céréales, l'orge et le maïs, et 2 aliments riches en fibres, les pulpes de betterave et la paille. Les sachets de nylon $(12 \mathrm{~cm} \times 7,5 \mathrm{~cm}$ de taille, $63 \mu$ de porosité) ont été incubés dans le rumen pendant $4,8,16,24$, et 48 heures. Deux répétitions ont été réalisées par animal. La dégradabilité aux différents temps d'incubation a été utilisée pour calculer la cinétique de dégradation dans le rumen dont l'équation proposée par $\emptyset$ rskov et Mc Donald (1979) est de type :

$$
d=a+b\left(1-\mathrm{e}^{-c t}\right)
$$

La dégradabilité théorique (DT) a été calculée à partir de l'équation rapportée par Mc Donald (1981) dont la formule est :

$$
\mathrm{DT}=a+(b c / c+k)
$$

où $k$, le taux de sortie des particules du rumen, a été estimé à $6 \%$ par heure (Vérité et al, 1987, Michalet-Doreau et al, 1987). En outre, la dégradabilité des matières azotées et de l'extrait éthéré a été déterminée sur les trois tourteaux. Finalement, il a été procédé à la détermination de la teneur en acides gras dans les tourteaux de colza et de lin ainsi que dans leurs résidus d'incubation.

La caractérisation des paramètres de fermentation a été réalisée à partir de prélèvements de liquide de rumen obtenus à intervalles de 2 heures pendant une période de 14 heures commençant avant le repas du matin. Une solution de thiomersal à $3 \%$ a été ajoutée au liquide en vue de bloquer les fermentations. Le $\mathrm{pH}$ a été déterminé immédiatement après le prélèvement par un potentiomètre à électrode $\mathrm{Ag} / \mathrm{AgCl}$. Les prélèvements ont ensuite été stockés au congélateur en vue de la détermination ultérieure de la concentration en acides gras volatils, en ammoniaque, en glucose et azote alpha-aminé.

\section{Méthodes analytiques}

La matière sèche a été dosée par dessication durant 24 heures à $105^{\circ} \mathrm{C}$, l'extrait éthéré par extraction à l'éther diéthylique et les cendres par calcination durant 24 heures à $550^{\circ} \mathrm{C}$.

Les teneurs en matières azotées totales ont été déterminées par la méthode de Kjeldahl $(\mathrm{N} \times 6,25)$ et la lignocellulose (fraction ADF des constituants pariétaux) selon la méthode de Van Soest (1963). 
Dans le jus du rumen, l'ammoniaque a été dosée selon la méthode de Berthelot adaptée à l'auto-analyser par Van Eenaeme et al (1969), le glucose par la méthode à l'orthotoluidine (Charlier et al, 1974) ; l'azote alpha aminé a été évalué par la technique au trinitrobenzène sulfonate (Palmer et Peters, 1969) et les acides gras volatils par chromatographie en phase gazeuse (Van Eenaeme et al, 1965). Enfin, la composition en acide gras des tourteaux et des résidus a été réalisée par chromatographie en phase gazeuse, après extraction et saponification selon la technique de Ter Meulen et al (1975).

\section{Traitement statistique}

Les données ont été traitées suivant le modèle de deux carrés latin 4 x 4 combinés à partir duquel les effets traitements, périodes, carrés et animaux ont été analysés (Cochran et Cox, 1957).

\section{RÉSULTATS}

Les quantités consommées sont reprises pour les quatre rations dans le tableau III. Ces quan- tités correspondent à l'ingestion totale de la ration incluant la paille. Pour la ration témoin soit le niveau 0 de tourteau de colza ( $0 \mathrm{~T}$ colza), les consommations ont été particulièrement élevées soit $10,8 \mathrm{~kg} /$ jour ou $1,95 \mathrm{~kg} / 100 \mathrm{~kg}$ de poids vif ou encore $94,3 \mathrm{~g} / \mathrm{kg}$ de poids métabolique. La consommation des rations contenant le tourteau de colza a également été très élevée et proche de celle de la ration de référence. Il n'y a pas eu d'effet significatif du niveau d'incorporation du tourteau de colza sur les ingestions. Les coefficients de digestibilité apparente des rations sont repris dans le tableau III. De manière générale, c'est avec la ration dont les matières azotées des tourteaux provenaient à raison d'un tiers du tourteau de colza ( $1 / 3 \mathrm{~T}$ colza) que les coefficients de digestibilité de tous les composants, à l'exception de l'extrait éthéré, ont été les plus élevés et c'est avec la ration $3 / 3 \mathrm{~T}$ colza que les coefficients ont été les plus faibles ; les différences entre 1/3 T colza et $3 / 3 \mathrm{~T}$ colza ont été significatives au seuil $p<0,05$. Les coefficients de digestibilité apparente du tourteau de colza, calculés par différence sont donnés dans le tableau IV. Les coefficients obtenus à partir de la ration $3 / 3 \mathrm{~T}$ colza ont été de $74,9 \%$ pour la MS, $76,5 \%$ pour la matière organique, $69,9 \%$ pour les matières

Tableau III. Ingestion et coefficients de digestibilité des rations.

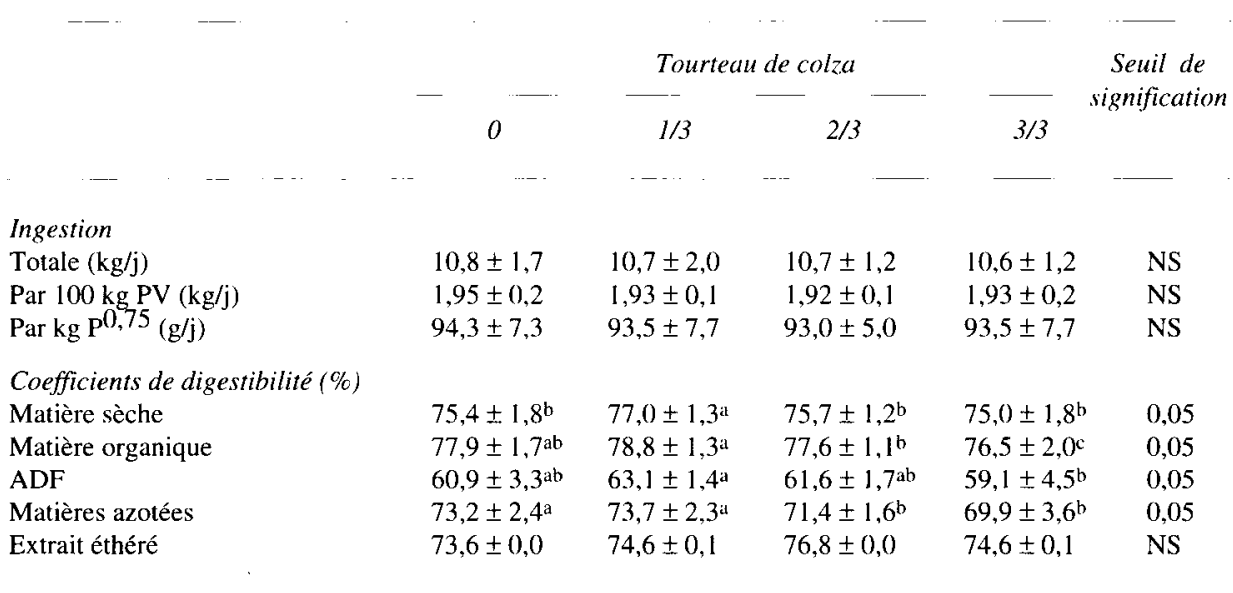

Les valeurs suivies de lettres différentes dans une même ligne sont significativement différentes. NS : non significatif au seuil de $p>0,05$. 
azotées, $59,1 \%$ pour la fibre ADF et de $74,6 \%$ pour l'extrait éthéré. Avec les deux autres taux d'incorporation, les coefficients ont été plus élevés ; les différences ayant été significatives avec la ration $1 / 3 \mathrm{~T}$ colza pour la MS $(p<0,05)$, les matières azotées $(p<0,05)$, la matière organique $(p<0,05)$ et les fibres $(p<0,05)$.

La dégradabilité théorique (DT) de la MS des huit aliments incubés dans le rumen est donnée dans le tableau $V$. De manière globale, c'est avec la ration $1 / 3 \mathrm{~T}$ colza que les dégradabilités théoriques ont été les plus élevées. Les dif- férences entre rations ont été significatives pour le tourteau de soja, les pulpes séchées et la paille $(p<0,05)$. Il faut noter que de semblables observations avaient déjà été rapportées pour les coefficients de digestibilité des rations et du tourteau de colza. Les paramètres décrivant la cinétique de la dégradabilité de la MS, des matières azotées et des matières grasses du tourteau de colza sont repris dans le tableau VI et comparés aux données relatives aux tourteaux de lin et de soja. De ces données, il apparaît que la MS et les matières azotées des tourteaux de

Tableau IV. Coefficients de digestibilité du tourteau de colza calculés par différence.

\begin{tabular}{cccc} 
Tourteau de colza & & $\begin{array}{c}\text { Seuil de } \\
\text { signification }\end{array}$ \\
\hline $1 / 3$ & $2 / 3$ & $3 / 3$ &
\end{tabular}

Coefficients de digestibilité $(\%)$

Matière sèche

Matière organique

$\begin{array}{ll}77,0 \pm 1,4^{\mathrm{a}} & 75,7 \pm 1,3^{\mathrm{ab}} \\ 78,8 \pm 1,4^{\mathrm{a}} & 77,5 \pm 1,2^{\mathrm{ab}} \\ 73,7 \pm 2,5^{\mathrm{a}} & 71,4 \pm 1,7^{\mathrm{ab}} \\ 63,1 \pm 1,5^{\mathrm{a}} & 61,6 \pm 1,8^{\mathrm{ab}} \\ 74,6 \pm 5,1 & 76,8 \pm 3,0\end{array}$

$74,9 \pm 1,9$

0,05

Matières azotées

$74,6 \pm 5,1$

$76,8 \pm 3,0$

$76,5 \pm 2,1^{b}$

0,05

$69,9 \pm 3,9 b$

0,05

ADF

Extrait éthéré

$59,1 \pm 4,8^{b}$

0,05

$74,6 \pm 6,9$

NS

Les valeurs suivies de lettres différentes dans une même ligne sont significativement différentes. NS : non significatif au seuil de $p>0,05$.

Tableau V. Dégradabilité théorique de la matière sèche de 8 aliments incubés dans le rumen.

\begin{tabular}{|c|c|c|c|c|c|}
\hline & & & ns & & Seuil de \\
\hline & 0 & $1 / 3$ & $2 / 3$ & $3 / 3$ & \\
\hline Tourteau de colza & $56,9 \pm 6,7$ & $60,0 \pm 1,1$ & $56,9 \pm 1,9$ & $58,0 \pm 1,3$ & NS \\
\hline Tourteau de lin & $60,3 \pm 4,3$ & $62,5 \pm 2,4$ & $59,4 \pm 1,8$ & $60,2 \pm 4,0$ & NS \\
\hline Tourteau de soja & $66,9 \pm 2,8^{a}$ & $67,9 \pm 3,1^{a}$ & $64,6 \pm 0,4^{b}$ & $64,5 \pm 1,0^{b}$ & 0,05 \\
\hline Tourteau de soja protégé & $44,4 \pm 3,2$ & $43,1 \pm 2,9$ & $42,8 \pm 1,3$ & $42,7 \pm 0,5$ & NS \\
\hline Orge & $72,2 \pm 4,9$ & $75,6 \pm 2,6$ & $74,0 \pm 4,1$ & $71,2 \pm 3,3$ & NS \\
\hline Maïs & $39,5 \pm 0,8$ & $40,4 \pm 1,5$ & $40,0 \pm 2,1$ & $38,6 \pm 1,4$ & NS \\
\hline Pulpes séchées & $58,1 \pm 2,3^{a}$ & $58,4 \pm 1,2^{\mathrm{a}}$ & $57,0 \pm 3,1^{\mathrm{ab}}$ & $55,2 \pm 1,8^{b}$ & 0,01 \\
\hline Paille & $18,5 \pm 0,7^{b}$ & $20,6 \pm 1,0^{\mathrm{a}}$ & $18,5 \pm 1,3^{b}$ & $17,4 \pm 2,0^{c}$ & 0,001 \\
\hline
\end{tabular}

Les valeurs suivies de lettres différentes dans une même ligne sont significativement différentes. NS : non significatif au seuil de $p>0,05$. 
Tableau VI. Paramètres décrivant la cinétique de la dégradabilité de la matière sèche, des matières azotées et de l'extrait éthéré du tourteau de colza en comparaison avec le tourteau de soja et le tourteau de lin..

\begin{tabular}{|c|c|c|c|c|}
\hline & $a$ & $b$ & $c$ & $D T(\%)$ \\
\hline \multicolumn{5}{|l|}{ Matière sèche } \\
\hline $\mathrm{T}$ colza & $22,9 \pm 5,1^{a}$ & $56,7 \pm 4,8^{\mathrm{c}}$ & $0,10 \pm 0,01^{b}$ & $57,8 \pm 5,0^{\mathrm{c}}$ \\
\hline $\mathrm{T} \operatorname{lin}$ & $12,4 \pm 2,1^{c}$ & $72,2 \pm 2,6^{b}$ & $0,13 \pm 0,01^{a}$ & $61,6 \pm 4,2^{b}$ \\
\hline T soja & $19,5 \pm 2,1^{b}$ & $79,4 \pm 1,1^{a}$ & $0,08 \pm 0,01^{\mathrm{c}}$ & $65,4 \pm 2,6^{\mathrm{a}}$ \\
\hline T soja protégé & $19,2 \pm 0,1^{b}$ & $73,6 \pm 6,5^{b}$ & $0,03 \pm 0,00^{d}$ & $43,6 \pm 2,6^{d}$ \\
\hline Seuil de signification & 0,05 & 0,001 & 0,001 & 0,001 \\
\hline \multicolumn{5}{|l|}{ Matières azotées } \\
\hline$T$ colza & $47,4 \pm 4,5^{c}$ & $46,7 \pm 3,6^{\mathrm{a}}$ & $0,07 \pm 0,01^{\mathrm{b}}$ & $71,7 \pm 1,9 \mathrm{c}$ \\
\hline $\mathrm{T}$ lin & $55,4 \pm 8,8^{b}$ & $41,2 \pm 9,3^{b}$ & $0,12 \pm 0,04^{\mathrm{a}}$ & $82,9 \pm 3,0^{b}$ \\
\hline T soja & $68,1 \pm 2,2^{\mathrm{a}}$ & $31,5 \pm 2,3^{d}$ & $0,08 \pm 0,01^{b}$ & $86,1 \pm 1,1^{a}$ \\
\hline T soja protégé & $40,2 \pm 5,6^{d}$ & $34,1 \pm 5,2^{\mathrm{c}}$ & $0,03 \pm 0,01^{c}$ & $51,8 \pm 2,2^{d}$ \\
\hline Seuil de signification & 0,001 & 0,001 & 0,001 & 0,001 \\
\hline \multicolumn{5}{|l|}{ Extrait éthéré } \\
\hline T colza & $31,4 \pm 4,5^{a}$ & $65,3 \pm 7,3^{b}$ & $0,09 \pm 0,01^{\mathrm{a}}$ & $70,5 \pm 3,8^{a}$ \\
\hline $\mathrm{T} \operatorname{lin}$ & $12,8 \pm 4,3^{b}$ & $76,6 \pm 6,9 a$ & $0,09 \pm 0,01^{\mathrm{a}}$ & $57,9 \pm 6,8^{b}$ \\
\hline Seuil de signification & 0,001 & 0,001 & NS & 0,001 \\
\hline
\end{tabular}

$\mathrm{DT}=a+(b c / c+k)$ où $a$ est la fraction rapidement dégradable ; $b$, la fraction potentiellement dégradable et $c$, la vitesse de dégradation de la fraction $b$. Les valeurs suivies de lettres différentes dans une colonne pour chaque composant sont significativement différentes. NS : non significatif au seuil de $p>0,05$.

soja et de lin utilisés ont été particulièrement dégradées dans le rumen. À l'opposé, le tourteau de soja protégé a été caractérisé, comme l'annonçait le fabricant, par une dégradabilité réduite. La fraction directement soluble dans le liquide de rumen a été significativement différente entre les quatre tourteaux pour la MS $(p<$ $0,05)$ et pour les matières azotées $(p<0,001)$. La vitesse de dégradation de la fraction non soluble, mais qui est dégradée, a été plus élevée pour la MS avec le tourteau de soja $(p<0,001)$. Le tourteau de colza utilisé dans la présente étude a présenté une DT comprise entre celle des tourteaux de soja et de lin et le tourteau de soja protégé. La disparition de l'extrait éthéré n'a été mesurée que pour le tourteau de colza et de lin vu la faible teneur en extrait éthéré des deux tourteaux de soja. L'extrait éthéré du tourteau de colza s'est révélé significativement plus dégradable que celui du tourteau de lin $(p<0,001)$.
Les paramètres de fermentation dans le rumen sont donnés dans le tableau VII. Il n'y a pas eu d'effets significatifs de l'incorporation de tourteau de colza sur le $\mathrm{pH}$ dans le rumen. Les fermentations ont été de type acétique puisque cet acide représentait plus de $60 \%$ des acides produits ; les proportions d'acides propionique et butyrique ont été classiques. Il en va de même pour la concentration en glucose. On notera cependant une faible tendance pour des concentrations quelque peu réduites en acides gras volatils totaux pour les taurillons qui avaient reçu la ration 3/3 T colza. Il faut signaler également que c'est avec la ration témoin que la concentration en ammoniaque a été la plus élevée et que c'est avec la ration $3 / 3 \mathrm{~T}$ colza que cette concentration a été la plus faible. Ces faibles différences peuvent être associées aux différences de dégradabilité des tourteaux de soja et de lin comparée à celle du tourteau de colza. 

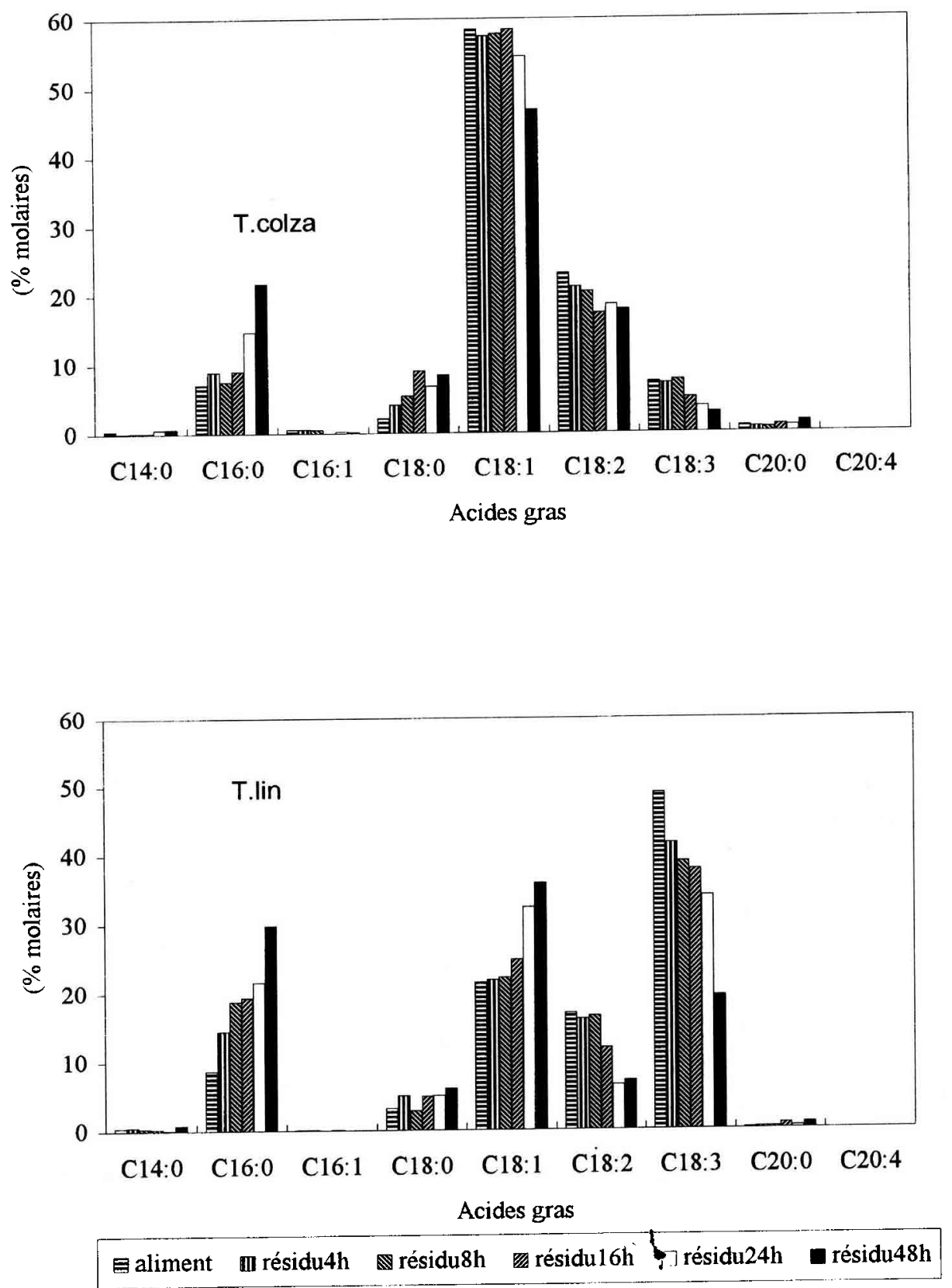

Fig 1. Acides gras dans le tourteau de colza et de lin ainsi que dans leurs résidus. 
Tableau VII. Caractéristiques de fermentation dans le rumen.

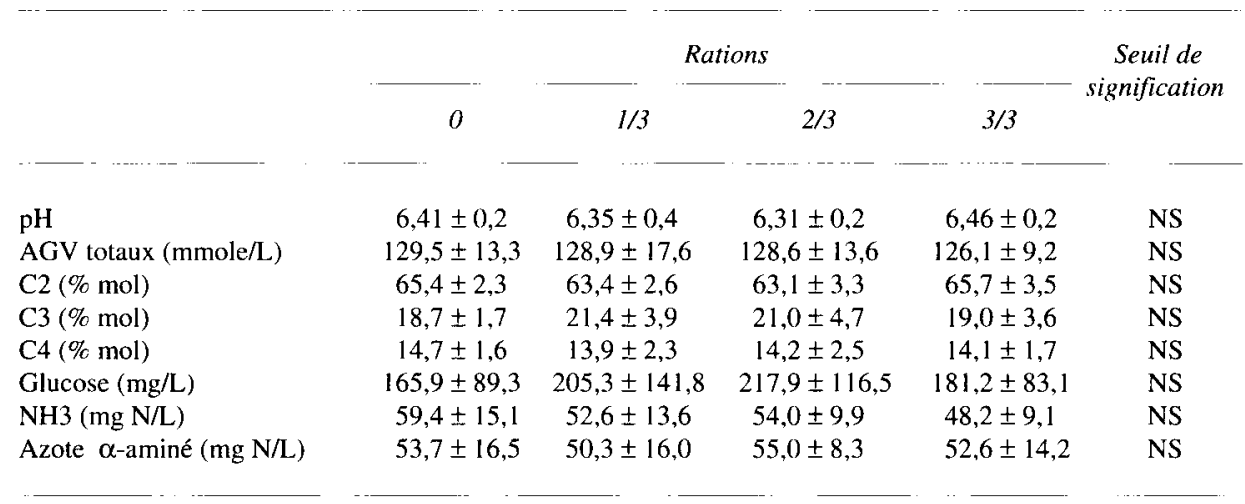

NS : non significatif au seuil de $p>0,05$.

Les compositions en acides gras des tourteaux de colza et de lin ainsi que des résidus d'incubation sont données dans la figure 1. Les teneurs observées dans les deux tourteaux étudiés ont été tout à fait classiques, c'est-à-dire des teneurs élevées en C18:1 (58,4\%) et en C18:2 $(23,1 \%)$ pour le tourteau de colza et en $\mathrm{C} 18: 3$ $(49,0 \%), \mathrm{C} 18: 1(21,6 \%)$ et C18:2 (17,0\%) pour le tourteau de lin. En ce qui concerne le tourteau de colza et à l'exception du résidu obtenu après 48 heures, il n'y a eu que peu de changements pour les teneurs en C18:1. Les teneurs en C18:2 des résidus ont quelque peu chuté pour les temps d'incubation longs $(p>0,05)$. La situation a été différente pour le tourteau de lin qui s'est caractérisé par une réduction importante des teneurs en $\mathrm{C} 18: 3$ à tous les temps d'incubation $(p<0,001)$, une réduction en C18:2 de 16 à 48 heures $(p<0,001)$ et une augmentation en $\mathrm{C1}$ 8:1. Pour les deux tourteaux, il faut noter une augmentation en $\mathrm{C} 16: 0$ et $\mathrm{C} 18: 0$ avec l'allongement de la durée d'incubation.

\section{DISCUSSION}

Les teneurs en minéraux et oligoéléments du tourteau de colza étudié étaient élevées pour un sous-produit de ce type (tableau I) ; les concen- trations en Ca et $\mathrm{P}$ étaient particulièrement hautes tandis que celles en $\mathrm{Cu}, \mathrm{Zn}$ et $\mathrm{Mn}$ correspondent aux besoins de taurillons en croissanceengraissement si on se réfère aux normes proposées par Guéguen et Lamand (1980). Il en résulte que l'incorporation de tourteau de colza en formulation de mélange d'aliments permet de réduire la complémentation minérale. Ce tourteau a été également caractérisé par une teneur en extrait éthéré de $8,6 \%$. Cette teneur est une valeur classique pour des tourteaux expellers produits dans une huilerie dont la presse est couplée à une unité de prétraitement thermique. Une telle teneur en extrait éthéré a fait augmenter la concentration en matières grasses dans le mélange distribué aux taurillons qui est passée de $3,2 \%$ dans la ration témoin à $4,2 \%$ dans la ration 3/3 $\mathrm{T}$ colza. Cette augmentation d'une unité pour cent pourrait être associée à la réduction très faible et non significative des ingestions. Clinquart et al (1995), dans une synthèse concernant l'utilisation des matières grasses chez les bovins à l'engraissement, rapportent que l'incorporation de matières grasses entraîne une réduction de l'ingestion associée à une augmentation des gains de poids et donc une amélioration de l'indice de consommation. D'autre part, il est fréquemment rapporté que la réduction des ingestions dans des rations contenant du tour- 
teau de colza est liée à la présence de facteurs antinutritionnels spécifiques du colza. L'effet est d'autant plus marqué que le taux d'incorporation du tourteau est élevé (Lardy et Kerley, 1994) ou que le tourteau contient des teneurs élevées en glucosinolates $(55 \mu \mathrm{mol} / \mathrm{g}$ MS). En effet, d'après la revue de Hill (1991), il est apparu que les ingestions par des veaux étaient diminuées lorsque du tourteau de colza riche en glucosinolates était substitué à du tourteau de soja. À l'opposé, il n'y avait que peu d'effets négatifs lorsque le tourteau de colza était à faible teneur en glucosinolate $(13 \mu \mathrm{mol} / \mathrm{g} \mathrm{MS})$. L'incorporation de $3 / 3 \mathrm{~T}$ colza a réduit de manière significative, mais avec une faible intensité, le coefficient de digestibilité des rations surtout si l'on compare avec la ration $1 / 3 \mathrm{~T}$ colza. Cet effet pourrait être lié à l'apport accru de matières grasses. En effet, d'après Clinquart et al (1995), les tendances générales de l'incorporation de matières grasses sont une faible réduction de la digestibilité apparente de la MS, de la matière organique et des fibres, une augmentation importante de la digestibilité de l'extrait éthéré et des effets très variables sur la digestibilité des matières azotées. Il est vraisemblable que les effets peu marqués dans l'expérience présente au niveau des ingestions et de la digestibilité résultent de la faible augmentation du taux de matières grasses avec la ration $3 / 3 \mathrm{~T}$ colza. Les coefficients de digestibilité apparente de la MS et la matière organique du tourteau de colza (tableau IV) ont été très proches des valeurs rapportées par Doreau et Michalet-Doreau (1987) et Inra (1988), alors que la digestibilité de la fibre était quelque peu plus élevée dans l'expérience présente. La réduction de la digestibilité des matières azotées de la ration $3 / 3 \mathrm{~T}$ colza pourrait être liée à la présence de tanins qui se complexent aux matières azotées insolubilisant les protéines et inhibant les enzymes digestives (Leung et al, 1979 ; Fenwick, 1982 ; Zimmer et al, 1995). Il est intéressant de rappeler que c'est avec la ration 1/3 $\mathrm{T}$ colza que les coefficients de digestibilité du tourteau ont été les plus élevés (tableau IV). Cette observation corrobore les coefficients élevés déjà enregistrés pour la digestibilité de la ration. Ces effets pourraient être liés à la diversification des sources des matières azotées.

La dégradabilité théorique de la MS et des matières azotées a été supérieure avec les tourteaux de soja et de lin par rapport au tourteau de colza ou au tourteau de soja protégé (tableau VI). Une moindre dégradabilité du tourteau de colza a été rapportée par Mir et al (1984) et Deacon et al (1988). Subuh et al (1994), rapportent en outre, que la dégradabilité est d'autant plus faible que le tourteau de colza est à faible teneur en glucosinolates.

La disparition dans le rumen des matières grasses du tourteau de colza a été significativement plus élevée $(p<0,001)$ en comparaison avec celle du tourteau de lin (tableau VI). La disparition des matières grasses apparaît liée à l'aspect libre ou au contraire associée au contenu et aux parois des cellules végétales qui ont été détériorées ou non par les différents traitements. D'après Clinquart et al (1993), les traitements peuvent, en outre, modifier la composition en acides gras en augmentant la proportion d'acides gras à courte chaîne et la proportion d'acides gras saturés. D' après Dufrasne et al (1991), la disparition de l'extrait éthéré après 8 heures d'incubation a été de $81,1 \%$ pour un mélange composé de $80 \%$ de son et de $20 \%$ d'huile de soja, et de $45,9 \%$ pour des fèves de soja toastées. La disparition de l'extrait éthéré de graines de lin floconnées sur support d'orge a été de 42,7 ; 57,$4 ; 69,1 ; 71,7$ et de $85,9 \%$ respectivement après $2,4,8,16$ et 24 heures d'incubation (Dufrasne et al, 1991). Dans une comparaison portant sur la disparition des matières grasses dans le rumen, Perrier et al (1992), rapportent que les lipides contenus dans le grain de maïs disparaissent plus rapidement et de manière plus intense que ceux de fève de soja, de tourteau de soja ou de foin de luzerne. Cette observation concorde avec celle de Valentine et Bartsch (1988) concernant la disparition des lipides d'orge comparés à ceux de lupin. Ces différents résultats confirment l'influence des structures cellulaires et membranaires sur le devenir des lipides dans le rumen. Il est vraisemblable que le prétraitement thermique des graines de colza 
avant la phase d'extraction de l'huile a détérioré de manière intense la structure pariétale des cellules améliorant le rendement d'extraction - ce qui était le but recherché - et a permis la disparition dans le rumen d'une partie de l'huile résiduelle. Le tourteau de lin, utilisé dans le cadre de cette étude, provenait du circuit commercial classique ; aucune donnée technique n'était disponible concernant sa production.

Les acides gras du tourteau de colza apparaissent comme mieux protégés contre l'hydrogénation par les microorganismes du rumen que ceux du tourteau de lin (fig 1). D'après Clinquart et al (1991), les acides gras provenant d'huile de soja ajoutée à du son comme support ont été particulièrement hydrogénés en comparaison aux acides gras de graines de lin floconnées sur support d'orge. Des observations semblables ont été rapportées par Steele et al (1971) et Murphy et al (1987) avec des fèves de soja et des graines de colza broyées. Il semble donc qu'une partie des matières grasses soit restée abritée à l'intérieur des structures cellulaires ou pariétales. En ce qui concerne le tourteau de lin, l'hydrogénation a été importante pour le C18:3 et le C18:2 dont les teneurs ont été réduites de plus de moitié après 48 heures d'incubation alors que la teneur en C18:1 a augmenté. Il est vraisemblable que ces modifications soient à associer à une moins bonne protection cellulaire. Il est à noter cependant que, d'après Doreau et Ferlay (1994), l'intensité de l'hydrogénation du C18:3 n'augmente pas de manière proportionnnelle à sa concentration dans l'aliment contrairement à d'autres acides gras tels que le C18:2.

Le tourteau de colza, avec une teneur en matières azotées de $37,8 \%$, se classe dans la catégorie des tourteaux très riches en matières azotées. Il s'agit en outre d'un tourteau dont les matières azotées sont moyennement dégradables, comme en témoigne la valeur de $71,7 \%$ pour la DT. Cette valeur est très proche de celle rapportée par ARC (1984). Cette plus faible dégradabilité a été corroborée par une réduction de la teneur en ammoniaque observée dans le liquide de rumen lorsque seul le tourteau de colza était utilisé. Les teneurs en PDI, calcu- lées à partir des données expérimentales en suivant la procédure décrite par Sauvant et al (1987), ont été respectivement de 259 et de $152 \mathrm{~g}$ de PDIN et PDIE par $\mathrm{kg}$ de MS. De même, il a été possible de déterminer des teneurs en énergie qui étaient de 1,11 UFL et de 1,07 UFV par kilo de MS. Ces valéurs sont données dans le tableau I et se rapprochent de celles rapportées par Inra (1988).

En conclusion, de la comparaison des quatre niveaux d'incorporation du tourteau de colza, il apparait que c'est la ration $1 / 3 \mathrm{~T}$ colza qui a permis d'obtenir les coefficients de digestibilité les plus élevés ainsi que la meilleure capacité de dégradabilité d'aliments de composition très variable tels que céréales, aliments riches en fibres ou matières azotées. De telles constatations suggèrent l'intérêt à diversifier les sources de tourteaux en vue d'optimiser la capacité de fermentation dans le rumen sans toutefois pouvoir dans le cas présent associer l'effet bénéfique à la nature des matières azotées ou à un apport supplémentaire en acides gras.

\section{REMERCIEMENTS}

Cette recherche a été réalisée grâce à la collaboration financière de la région wallonne (Namur, Belgique).

\section{RÉFÉRENCES}

ARC (Agricultural Research Council) (1984) The nutrient requirements of ruminant livestock. Commonwealth Agricultural Bureaux, Farnham Royal, UK, Suppl 1, 45 p

Bell JJ (1984) Nutrients and toxicants in rape-seed meal: a review. J Anim Sci 58, 996-1010

Charlier C, Van Eenaeme C, Canart B, Pondant A, Lambot O, Bienfait JM (1974) Méthode de dosage semi-automatique de l'amidon et du glucose dans les aliments pour bétail. Ann Méd Vét 118, 181194

Clinquar A, Istasse L, Dufrasne I, Mayombo AP, Van Eenaeme C, Bienfait JM (1991) Effects on animal performance and fat composition of two fat concen- 
trates in diets for growing-fattening bulls. Anim Prod 53, 315-320

Clinquart A, Istasse L, Van Eenaeme C, Diez M, Dufrasne I, Bienfait JM (1993) Effects of extrusion of linseed mixed with barley, pea mixed with rape-seed and soya bean on degradability in the rumen of nitrogen and ether extract and on fatty acid composition. Ann Zootech 42, 130-131

Clinquart A, Micol D, Brundseaux C, Dufrasne I, Istasse L (1995) Utilisation des matières grasses chez les bovins à l'engraissement. Inra Prod Anim $8,29-42$

Cochran WG, Cox GM (1957) Completely randomized, randomized block, and latin square designs. In : Experimental Designs (J Wiley \& Sons), Canada, 95-147

Deacon MA, De Boer G, Kennelly JJ (1988) Influence of Jet-Sploding and extrusion on ruminal and intestinal disappearance of canola and soya beans. J Dairy $S_{c i}$ 71, 745-753

Doreau M, Michalet-Doreau B (1987) Tourteaux et graines de colza et de tournesol : utilisation digestive par les ruminants. Bull Tech CRZV Theix Inra $68,29-39$

Doreau M, Ferlay A (1994) Digestion and utilisation of fatty acids by ruminants. Anim Feed Sci Technol $45,358-365$

Dufrasne I, Istasse L, Van Eenaeme C, Clinquart A, Bienfait JM, Thewis A (1991) Notes sur la dégradabilité dans le rumen de 6 aliments riches en matière grasse. Rev Agric 44, 31-38

Fenwick GR (1982) The assessment of a new protein source - rapeseed. Proc Nutr Soc 41, 277-288

Guéguen L, Lamand M (1980) Eléments minéraux majeurs In : Alimentation des ruminants ( $\mathrm{R}$ Jarrige, ed), Inra-Éditions, Paris (2e édition), 129. 159

Hill R ( 1991) Rapeseed meal in the diets of ruminants. Nutr Abst Rev 61, 140-155

Inra (1988) Alimentation des bovins, ovins et caprins (R Jarrige, ed). Inra-Éditions, Paris, 47 l $p$

Lardy GP, Kerley MS (1994) Effect of increasing the dietary level of rapeseed meal on intake by growing beef steers. J Anim Sci 72, 1936-1942

Leung J, Fenton TW, Meuller MM, Clandinin DR (1979) Condensed tannins of rapeseed meal. $J$ Food Sci 44, 1313-1316

Mc Donald I (1981) A revised model for the estimation of protein degradability in the rumen. J Agric $S_{C i}$ Camb 96, 251-252
Mehrez AZ, Ørskov ER (1977) A study of the artificial fibre bag technique for determining the digestibility of feeds in the rumen. J Agric Sci Camb 88, 645-650

Michalet-Doreau B, Vérité R, Chapoutot P (1987) Méthodologie de mesure de dégradabilité in sacco de l'azote des aliments dans le rumen. Bull Tech CRZV Theix Inra 69, 5-7

Mir Z, Macleod GK, Buchanan-Smith JG, Grieve DG, Grovum WL (1984) Methods for protecting soyabean and canola proteins from degradation in the rumen. Can J Anim Sci 64, 853-865

Murphy M, Uden P, Palmquist DL, Wiktorsson H (1987) Rumen and total diet digestibilities in lactating cows fed diets containing full-fat rapeseed. J Dairy Sci 70, 1572-1582

Ørskov ER, Mc Donald I (1979) The estimation of protein degradability in the rumen from incubation measurements weighed according to rate of passage. J Agric Sci Camb 92, 499-503

Palmer DW, Peters JT (1969) Automated determination of free amino groups in serum and plasma using 2, 4, 6 trinitrobenzene sulfonate. Clinic Chem 19, $891-901$

Perrier R, Michalet-Doreau B, Bauchart D, Doreau M (1992) Assessment of an in-situ Technique to Estimate the Degradation of Lipids in the Rumen. I Sci Food Agric 59, 449-455

Sauvant D, Aufrère J, Michalet-Doreau B, Giger S, Chapoutot $P$ (1987) Valeur nutritive des aliments concentrés simples : tables et prévision. Bull Tech CRZV Theix Inra 70, 75-89

Schneider BH, Flatt WP (1975) Digestibility by Difference. In : The Evaluation of Feeds Through Digestibility Experiments. The University of Georgia Press, Athens, 151-188

Steele W, Noble RC, Moore JH (1971) The relationship between plasma lipid composition and milk fat secretion in cows given diets containing soybean oil. J Dairy Res 38, 57-64

Subuh AMH. Rowan TG, Lawrence TLJ (1994) Effect of heat or formaldehyde treatment and differences in basal diet on the rumen degradability of protein in soyabean meal and in rapeseed meals of different glucosinolate content. Anim Feed Sci Technol 9, 297-310

Ter Meulen VU, Nordbeck H, Molnar S (1975) Untersuchungen zur Morphologie und Physiologie des perirenalen Fettgewebes beim Kalb und der Einfluss der Umgebungstemperatur auf seine Funktion 2 Mitteilung Methodik und Versuchsergeb- 
nisse (Versuch I und II). Z Tierphysiol Tierernähr Futtermittelk 35, 144-163

Valentine SC, Bartsch BD (1988) Degradation of dry matter, crude protein, fat, crude fibre and nitrogen-free-extract in milled barley and lupin grains incubated in nylon bags in the rumen of dairy cows. J Agric Sci, Camb 110, 395-398

Van Eenaeme C, Bienfait JM, Lambot O (1965) La détermination quantitative des acides gras volatils dans le liquide du rumen par chromatographie en phase gazeuse. Ann Méd Vét 109, 569-584

Van Eenaeme C, Bienfait JM, Lambot O, Pondant A (1969) Détermination automatique de l'ammoniaque dans le liquide de rumen par la méthode de Berthelot adaptée à l'Auto-analyzer. Ann Méd Vét $113,419-429$

Van Soest PJ (1963) Use of detergent in the analysis of fibrous feeds. II. A rapid method for the determination of fiber and lignine. J Ass Off Agr Chem 46, 829-835

Vérité R, Michalet-Doreau B, Chapoutot P, Peyraud J L, Poncet C (1987) Révision du système des proteines digestibles dans l'intestin (PDI). Bull Techn CRZV Theix, Inra 70, 19-34

Zimmer N, Cordesse R, Inesta M, Fabre D (1995) Influence des tanins hydrolysables de châtaignier sur le métabolisme azoté des ovins et des caprins. Ann Zootech 44, 227 